\title{
O PODER DA COMUNICACÃO DO CONSUMIDOR NAS REDES SOCIAIS - UMA ANÁLISE MERCADOLÓGICA DA MARCA RISQUÉ
}

\section{Priscila GUIDINI*}

\section{RESUMO}

A internet chegou como um fenômeno sem precedentes em nossa sociedade transformando as relações sociais, comerciais e organizacionais. A interatividade e a exposição das marcas na rede deram poder ao novo consumidor. Com voz de comando, os consumidores conectados ditam as regras e cobram das organizações tudo aquilo que enxergam como seu direito. Sem entender ao certo como se posicionar diante desse novo comportamento, as organizações e as instituições estão perdidas. Esse artigo busca analisar a comunicação desse consumidor que tem o poder do discurso e da exposição ao alcance de suas mãos. A proposta consiste em entender melhor a convergência que vem propiciando uma era na qual o discurso corporativo e a mídia alternativa se encontram e os poderes do assessor de imprensa e do consumidor interagem de maneira equivalente.

Palavra-chave: Poder. Consumidor. Internet. Comunicação

\section{INTRODUÇA}

A internet chegou como um fenômeno de transformação da sociedade, já que impulsionou grandes alterações em diversos aspectos da vida dos indivíduos, pois a rede mundial de computadores gera conteúdo e informação na velocidade de um clique. Esse fato possibilitou às corporações estabelecerem novos canais de distribuição e de contato com seus consumidores. A velocidade com que essas transformações impactaram a sociedade ainda

* Docente dos cursos de Marketing e Administração do Centro Universitário Antônio Eufrásio de Toledo. Mestranda do Programa de Pós-Graduação Strictu Sensu em Comunicação Social da Universidade Metodista de São Paulo (Poscom). E-mail: priguidini7@gmail.com 
não é bem compreendida pelas empresas que se deparam com uma comunicação de total interatividade na qual os consumidores, de forma individual ou organizados em grupos, conseguem uma extrema visibilidade de suas interações com as marcas.

A nova tecnologia criou um espaço de intersecção entre os antigos e os novos meios de comunicação, uma nova cultura, da qual o público exige participação.

Essa foi a mudança mais drástica que passou a fazer parte da comunicação organizacional, visto que as mídias digitais tornaram as empresas grandes vitrines e, pela primeira vez, a comunicação passou a acontecer de muitos para muitos, bem como de muitos para poucos e, ainda, de um para um.

Nesse cenário digital, implicitamente dialógico, autônomo, espontâneo e contribuinte, o consumidor se vê empoderado, pois enxerga que a transparência total oferecida pela rede lhe permite desafiar qualquer autoridade. $\mathrm{O}$ consumidor passa, então, a exercer o seu poder. Em 2009, Javier Cremades já havia relatado o micropoder do consumidor como uma das forças emergentes mais proeminentes do novo século. Como mostram Nordström e Riddestrale (2001, p. 82) "o controle foi transferido tacitamente para as mãos de dezenas de milhões de usuários no mundo todo - em breve serão centenas de milhões. Este é apenas o começo". Unidos em sociedades cada vez mais organizadas, os neoconsumidores digitais se fazem ouvir e gritam aos ouvidos organizacionais.

\section{A COMUNICACÃO NA ERA DIGITAL}

A comunicação mudou. $\mathrm{O}$ antigo esquema que a definia como uma ação na qual há um emissor, um receptor e uma mensagem, já está ultrapassado. Figaro (2010, p.4) a conceitua como

o processo que se realiza na/pela interação de sujeitos determinados, históricos e que se inter-relacionam a partir de um contexto, compartilhando sistemas de códigos culturais e, ao fazê-lo, atuam (agem) produzindo/ renovando sociedade.

A linguagem constitui, portanto, um veículo de interação social e, desse modo, as mudanças sociais têm impacto na forma como os indivíduos se comunicam, visto que a tecnologia promoveu uma profunda mudança social que alterou a relação entre emissor e receptor.

A internet transformou a comunicação e a maneira como a mensagem chega até os seus mais diversos públicos. Aliás, a mensagem não é mais a mesma, porquanto hoje assistimos à comunicação multicanal, com mensagens em diferentes linguagens e com receptores que são, também, autores e coautores de conteúdo. 
Galindo (2015, p. 14) alerta que as práticas consolidadas de comunicação, que definiam as estratégias de mercado, se encontram fragilizadas ou desajustadas. Afirma, também, que a revolução no processo de comunicação parece sem fim, pois, para ele, as ferramentas tecnológicas permitiram que a comunicação de massa convivesse com uma variedade de meios e, nesse sentido, as novas formas de se comunicar dizem respeito, também, a novas formas de produzir e de distribuir conteúdos comunicativos nos mais diversos meios com uma imensa pulverização.

Nesse sentido, as novas tecnologias poderão contribuir ainda mais na segmentação e na direcionalidade das mensagens, ou seja, a desmassificação dos meios e a possibilidade de uma intermediação semelhante ao processo interpessoal, portanto, mais relacional e próximo do consumidor. (GALINDO, 2008).

Fica claro, portanto, que a comunicação hoje é muito mais pessoal. O ciberespaço permite que o internauta fale diretamente com instituições, empresas e entidades, podendo, ainda, divulgar publicamente o seu diálogo. Portanto, esse novo espaço público criou uma comunicação relacional entre consumidores e empresas.

O olhar agora deve ser voltado para uma tecnologia que permita, além da comunicação, o relacionamento entre todas as partes e, nesse contexto, o internauta assume papel fundamental no que diz respeito à imagem das empresas, pois as suas opiniões sobre determinada companhia podem ser vistas por toda a comunidade virtual.

As redes sociais digitais têm mostrado o quanto os consumidores atuais querem se manifestar, haja vista o grande número de compartilhamento de buscas, de compras, de experiências e de relacionamentos. O poder de influência das opiniões online é gigantesco e tem feito as organizações, dos mais diversos segmentos, modificarem a comunicação com seus stakeholders. Nesse sentido, a comunicação deve ter, como meta, promover o engajamento. Engajar, segundo a definição de Galindo (2015, p.47), constitui “uma maneira de ser e pensar, mas, acima de tudo, é uma postura colaborativa e de mutualidade e de geração e manutenção contínua da confiança”.

\section{O CONSUMIDOR NAS REDES SOCIAIS DIGITAIS E A INSTITUICÕES SOCIAIS}

A popularização da internet trouxe consigo mudanças comportamentais em todas as esferas sociais, pois a sociedade entrou para a rede e passou a entender a dimensão de suas interações comunicacionais nesse novo espaço. 
A banda larga possibilitou à população em massa fácil acesso às redes sociais digitais. Nesse momento uma vitrine se descortinou e as interações digitais trouxeram à tona informações antes restritas ou filtradas por veículos de comunicação de massa e pelo Estado. Ao ter acesso aos mais diversos tipos de informação, a população passou a se posicionar diante dos cenários que começou a conhecer e, nesse sentido, Castells (1999) acredita que as ferramentas tecnológicas atenderam demandas sociais, econômicas e culturais, fragilizando as tradicionais estruturas do Estado, uma vez que a massa, insatisfeita com sua realidade, passou a exigir os seus direitos de forma organizada.

$\mathrm{O}$ indivíduo com informação engajou-se digitalmente, fato que acarretou no movimento conhecido como ciberativismo. $\mathrm{O}$ ativismo pode ser descrito "como qualquer doutrina ou argumentação que privilegie a prática efetiva de transformação da realidade, através da formação de um grupo de pessoas organizadas para um determinado objetivo". Enxerga-se, assim, o ativismo como uma militância organizada em busca de mudanças. $\mathrm{Na}$ internet, o ativismo passou a ser digital e ganhou proporção mundial com a aglutinação de um número extraordinário de pessoas que comungam da mesma causa.

Esse movimento nas redes sociais digitais ganhou força nos mais diversos níveis, como, por exemplo, reivindicações políticas, em esfera nacional, até solicitações para a resolução do problema de enchentes em um bairro.

Diante das possibilidades, os ativistas digitais optam principalmente por causas que não ganhavam destaque na mídia tradicional - a principal curadora e porta-voz dos assuntos que mereciam atenção. $\mathrm{O}$ internauta pode brigar pela proteção das baleias e também por questões mais práticas de seu dia a dia. (CARPANEZ, 2015).

A distância entre as questões sociais e o ativismo está a um clique. $\mathrm{O}$ site change.org, que possui uma versão brasileira, constitui um bom exemplo, visto que, nesse espaço, qualquer cidadão pode expor sua causa e realizar um abaixo-assinado. Para ter uma ideia da eficiência do site, ele já alcançou um volume de assinaturas que conseguiu resolver mais de 15 mil reivindicações, em 196 países, dentre as quais, a inclusão de atletas profissionais do sexo feminino no jogo de videogame Fifa e a exclusão de taxas adicionais que uma escola estaria cobrando para acolher crianças com deficiência.

Pagamento TonhoO ativismo digital tem sido visto como o "novo poder" que altera e assusta as instituições sociais a partir da organização nas redes digitais. Manuel Castells (2013), em sua obra Redes de Indignação e Esperança, afirma que 


\section{- UMA ANÁLISE MERCADOLÓGICA DA MARCA RISQUÉ}

a velocidade da organização que a internet permitiu extrapolou a capacidade de repressão estatal devido a sua não compreensão dos métodos organizacionais desses grupos rebeldes que se utilizaram de redes sociais como ferramentas de comunicação horizontal.

Para embasar a sua tese, o autor cita eventos decorrentes da organização social, ocorridos em várias partes do mundo, como a Primavera Árabe, o movimento espanhol Los Indignados e o Movimento Passe Livre, oriundo no Brasil.

Os diálogos, nas redes sociais virtuais, constituem produtos de uma discussão coletiva, como negociações informais, porém reais, nas quais acontece a dinâmica do acordo e do conflito.

É nítido o poder transformador social da comunicação nesse ambiente, onde o indivíduo, reunido em grupo, com a força de seus pares, ganha uma imensa relevância. Tal modelo de comunicação vem sendo tão eficaz que amedronta as instituições sociais e o próprio Estado, que, sem saberem exatamente como agir, estão cautelosos. Em alguns momentos eles se fecham em seu universo e, em outros, cedem às pressões, acreditando que o buzz pode ser maior caso endureçam.

Tal vulnerabilidade tem sido combustível para novas intervenções sociais e ainda que se diga que se trata de um "ativismo de sofá", essas interações provocam mudanças nos mais variados segmentos institucionais. Vale ressaltar que e esse movimento ainda está em processo e que o seu desfecho só será conhecido ao longo do tempo. Atualmente, o que se enxerga é um amplo poder nas mãos dos indivíduos que lutam virtualmente pelas causas que consideram justas e dão ainda mais visibilidade às lacunas deixadas pelo Estado e pelas instituições governamentais.

A consequência dessa nova atuação dos atores sociais, segundo a visão de Castells (2015), pode levar a sociedade a repensar a Democracia. De acordo com o autor, não se trata de destruir o capitalismo, mas sim de repensá-lo e de reestruturá-lo através de uma nova mentalidade, fundamental para a gestação de uma sociedade menos desarmônica.

\section{O CONSUMIDOR NAS REDES SOCIAIS DIGITAIS E SOCIEDADE}

Esse movimento, que se traduz em reivindicações e em lutas por direitos, exigindo posicionamentos de instituições sociais e do Estado, também impacta na sociedade de forma comercial, já que a rede proporciona uma infinidade de interações por meio das quais, grupos de interesse específico se encontram, ainda que, muito distantes geograficamente. Os relacionamentos digitais, nos mais diversos níveis, são cada vez mais constantes e possíveis. 
Tais interações mudam a forma como a sociedade está se organizando. O poder de influência dos formadores de opinião tem sido cada dia mais explorado, já que os blogs, por exemplo, direcionam a opinião e os pensamentos de um grande número de seguidores.

As comunidades colaborativas tornaram-se uma moeda social com valor incalculável, pois, nesses grupos, há trocas de conteúdos, de experiências, de utilização de produtos com altíssima influência sobre os seus componentes. Esse movimento impacta os negócios das empresas, que passam a contar com formadores de opinião por todos os cantos do mundo.

A expressão cultura participativa contrasta com noções mais antigas sobre passividade dos espectadores dos meios de comunicação. Em vez de falar sobre produtores e consumidores de mídia como ocupantes de papeis separados, podemos agora considera-los participantes interagindo de acordo com um conjunto de regras, que nenhum de nós entende por completo. (JENKINS, 2008. p.28)

Jenkins relata em sua obra, A Cultura da Convergência (2008, p.28), que os consumidores, por hora, ainda estão aprendendo a usar o poder da inteligência colaborativa, uma vez que, atualmente, ainda se restringe à recreação, mas, em pouco tempo, tal habilidade será utilizada com propósitos mais sérios.

No ambiente virtual, os indivíduos, que, antes, só compravam de varejistas, agora, comercializam produtos entre si; além disso, sites, como o Buscapé e o Bondfaro, apresentam, aos usuários, o preço de um mesmo produto em diversas lojas, afora os prazos de pagamentos oferecidos pelos lojistas, o que permite a escolha pela opção que mais se encaixa no perfil de cada indivíduo.

Dentro das empresas, funcionários conectados também se organizam, trocando ideias sobre as possíveis melhorias nas políticas salariais e nos benefícios oferecidos pelas organizações.

Desse modo, as interações sociais permitem que qualquer pessoa se conecte, monte sua rede de relacionamentos e faça negócios ou reivindicações a um custo próximo de zero. Pode-se inferir que tal movimento consiste em uma intensa mudança de cultura, poucas vezes vivenciada e por isso, será, efetivamente, sentida mais no longo prazo.

Cremades (2009, p. 49) discute o quanto o fenômeno da informação compartilhada vem sendo reforçado pelas enciclopédias de livre cooperação massiva, as wikis. Essas enciclopédias têm produzido um efeito fulminante sobre a ciência institucionalizada, uma vez que expõem informações abertamente, de forma gratuita. 


\section{O PODER DA COMUNICAÇÃO DO CONSUMIDOR NAS REDES SOCIAIS - UMA ANÁLISE MERCADOLÓGICA DA MARCA RISQUÉ}

A facilidade de acesso à informação provoca outra mudança de impacto social, a diminuição da memória social, visto que, ao entender que os dados estão ao alcance de um clique, o indivíduo se acomoda, deixando de arquivar seu conhecimento e sua história.

A acessibilidade a conteúdos de referência parece implicar o fim da memória como ferramenta educativa e para as tarefas humana de forma geral. Os conteúdos - e não estamos falando de textos educativos - que antigamente eram aprendidos de memória, e até poucos anos atrás eram estudados, estão cada vez mais ao alcance da mão. Há bem pouco tempo, boa parte do esforço educativo e laboral consistia em extrair (em se tratando de educação, era mais o caso de armazenar) esses conteúdos em algum lugar - memória ou arquivo -, algo que agora recebemos pronto. (JAVIER CREMADES, 2009, p. 50)

O autor, porém, compreende a importância do avanço tecnológico na sociedade e afirma que, embora haja perda de memória social e, talvez, de conhecimento adquirido, em virtude da massificação da internet, há, também, a livre distribuição de conhecimento a todos. Desse modo, a disponibilização de conteúdos culturais traz diversas oportunidades a uma sociedade interconectada.

É certo que os atores sociais mudaram seus comportamentos, ocasionando a perda de controle e de autonomia de instituições sociais, já que, hoje, os indivíduos organizados dão as cartas. Galindo (2015, p. 50) acrescenta que "a isso se soma a introdução constante de conhecimento, tecnologia, compartilhamento de informações e descrença nos canais oficiais, levando os atores sociais a ocuparem o centro das decisões e das escolhas (...)".

O poder da informação e a força da geração colaborativa alteram as estruturas da sociedade, deixando instituições e empresas sem saber qual caminho percorrer para chegar à razão e ao coração dos seus stakeholders. Ainda perdidas no universo cibernético, as entidades têm sido alvos de repreensões e de ataques de seus clientes, colaboradores e prospects.

\section{O CONSUMIDOR NAS REDES SOCIAIS DIGITAIS E AS MARCAS}

Não só a sociedade e as instituições sociais sentem o impacto causado pelo poder dos consumidores disseminado nas redes sociais. Uma das maiores mudanças consiste na relação das empresas e de suas marcas com seus consumidores. Em uma economia em rede a interatividade do ciberespaço altera a configuração do relacionamento das marcas com seus agentes de consumo de maneira radical, visto que os públicos, em geral, não aceitam mais somente comprar e consumir um produto, precisam emitir opinião, 
compartilhar suas conquistas e influenciar a decisão de compra de outros consumidores. Aquele tipo de comprador passivo e fiel não existe mais, porquanto a visibilidade concedida pelo espaço virtual faz do consumidor um defensor ou um crítico das marcas.

(...) temos o foco em um novo consumidor, ou ainda em um consumidor envolto por um forte e consistente relacionamento social no sentido quantitativo, pois apoiado em tecnologias como as das telecomunicações, como diz Joseph Jaffe (2008), esses consumidores "[...] em qualquer parte, a qualquer momento em qualquer lugar [...] acessar milhões de seus mais íntimos desconhecidos virtuais" (Jaffe, 2008, p.32). Sem dúvida é preocupante, mas real, esse relacionamento com os mais íntimos desconhecidos, ligados por interesses comuns e predispostos a trocar informações, compartilhar impressões, opiniões e, acima de tudo validar posições sobre qualquer tema. (GALINDO, 2015, p.15)

As marcas, hoje, se veem como reféns de seus próprios consumidores e de sua influência no meio digital, por isso, um tanto quanto perdidas, já que ainda não entendem a importância da comunicação e do relacionamento com seus públicos de interesse. Cremades (2009) afirma que as empresas precisam se adaptar às mudanças no modelo de negócios, que anteriormente visava apenas ao lucro e, atualmente, se baseia em relações, em links, em interconectividade e no compartilhamento de informações.

Conteúdo relevante, experiência e relacionamento parecem ser, atualmente, as palavras de ordem dentro do processo de comunicação das marcas com seus públicos, pois os consumidores querem interagir com a marca a todo momento. Nesse sentido, o marketing de interrupção é rejeitado pelos consumidores, que criam aversão às empresas que aparecem sem terem sido convidadas.

Galindo (2015, p. 39) relata que a multiplicação de canais e a interação de clientes em tempo real exigem que as marcas repensem a maneira de se relacionar com as pessoas, uma vez que, atualmente, relacionamento se refere ao novo status entre os atores sociais. De acordo com o autor, trata-se de uma visão realista da interatividade, de comunicação e de uma nova perspectiva sobre os atos de vender, de comprar e de se relacionar. O importante agora é usar a tecnologia para conhecer mais intimamente o cliente e suas manifestações, uma responsabilidade de interação dos sujeitos, não das máquinas.

Outro fator fundamental constitui a criação de um laço forte entre as marcas e seus consumidores. Kotler (2010) afirma que a comunicação e o marketing têm que olhar o consumidor como um ser humano com necessidades e esperanças que devem ser levadas em conta pelas empresas. $\mathrm{O}$ autor 
acredita, ainda, que o marketing entrou na era dos valores, por isso, as marcas devem concentrar suas ações em fazer um mundo melhor.

O consumidor exige esse posicionamento não só no discurso, mas também nas atitudes. As redes sociais digitais permitem que essas cobranças, bem como a comprovação da responsabilidade das empresas, se tornem públicas. Não há mais como esconder ou ludibriar esse consumidor que grita aos ouvidos das empresas com questões de todas as ordens e, muitas vezes, inclusive, sem coerência em suas reivindicações.

O caso Risqué, descrito a seguir demonstra a ausência de bom senso em reclamações públicas, o que coloca a marca em cheque e desgastam seu discurso.

O CASO RISQUÉ

A Risqué é uma marca líder de esmaltes no Brasil pertencente à gigante mundial Hypermarcas. Com uma história de meio século no mercado de produtos para beleza, lança tendências de moda, sempre olhando para a inovação e para os seus clientes. A marca costuma lançar duas coleções anuais, além de edições especiais, ditando a moda desse segmento. A empresa possui mais de 7 milhões de seguidores no Facebook e conta com um blog chamado Risqué a Vida em Cor, que traz novidades sobre cores, tendências da estação, além de um simulador interativo de esmaltes. Porém, toda essa interação não evitou a fúria de suas consumidoras.

Em 2016, a marca foi alvo de duas polêmicas envolvendo suas clientes. Em março, a empresa lançou a coleção Homens que Amamos, cujas cores de esmaltes tinham nomes de homens com atitudes de gentileza com as mulheres. Observe, abaixo, a lista com os nomes das cores:

- Léo Mandou Flores

- João Disse Eu te amo

- André Fez o Jantar

- Zeca Chamou Para Sair

- Guto Fez o Pedido

- Fê Mandou Mensagem 
Imagem das embalagens de esmaltes.

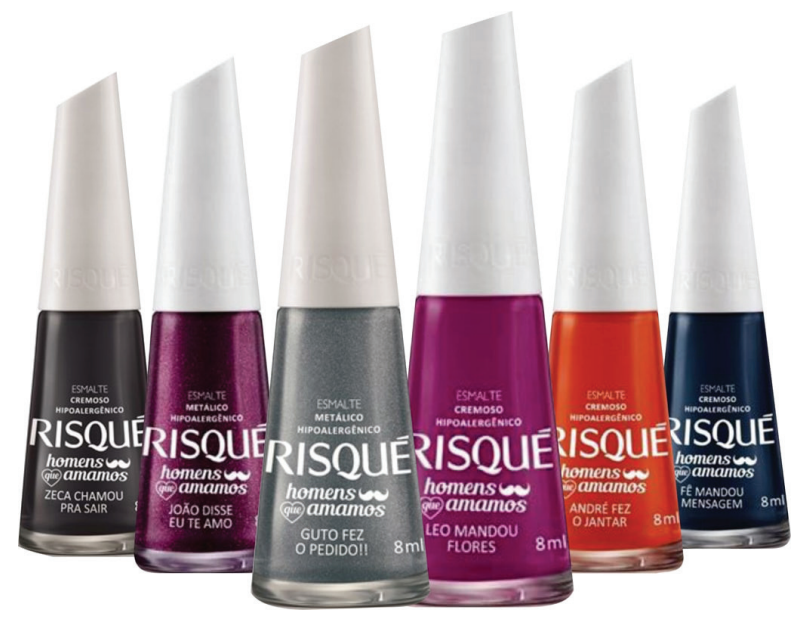

Fonte: internet

Ao lançar a campanha, a ideia da marca era unir romantismo e vaidade. Nas redes sociais online havia um contexto narrativo para o nome do esmalte "André sempre me surpreende: me esperou em casa com um incrível jantar à luz de velas".

Porém suas consumidoras não entenderam a estratégia da marca e bombardearam as redes sociais com o argumento de que a Risqué estava sendo machista ao imaginar que as mulheres precisam de atitudes masculinas para ser felizes. As internautas afirmaram, ainda, que as atitudes masculinas devem ser rotineiras e não celebradas ou merecedoras de homenagens especiais. Também houve a acusação de que a marca não pensou nas consumidoras homossexuais, pois, para elas, o nome dos esmaltes não faz nenhum sentido.

O erro da marca foi ter esquecido a pluralidade de pensamentos dos consumidores conectados, além de não ter considerado a ânsia que esse tipo de usuário tem em se expressar. Essa diversidade narrativa não prevista pela marca de cosméticos, promoveu um desalinhamento entre o seu objetivo de mensagem e a recepção ideológica de suas consumidoras. Gonçalves (2015) relata que vivemos em uma imensidão de narrativas e de ideologias. Além disso, acredita que as organizações não conseguem prever o impacto de sua comunicação.

Estamos rodeados de narrativas, elaboradas em diferentes semióticas, em ambientes e contextos diferenciados, com os mais diversos atores, mais próximos ou mais distantes do cotidiano, da realidade vivenciada. Trata-se de 
uma sucessão de estados e transformações, narrativas reais outras ficcionais, imaginadas, porém, são responsáveis por construírem a realidade do indivíduo em sociedade. (GONÇALVES, 2015, p. 56)

E os diálogos não são entendidos nem dentro das próprias tribos. Enquanto um grupo de consumidoras promoveu um levante contra os nomes nas embalagens dos esmaltes, muitas outras apoiaram a empresa, acreditando na sua intenção de trazer a gentileza e a leveza para a marca de cosméticos. Em uma enquete no blog UOL Mulher, as internautas foram questionadas sobre a campanha da Risqué e 79\% indicaram que acharam "boa, atitudes bonitas sempre merecem ser elogiadas". Fica evidente nessa narrativa, como a comunicação mercadológica passa por um momento de incertezas e de fragilidades diante do poder do consumidor.

A segunda polêmica vivida pela marca aconteceu apenas três meses depois do questionamento sobre os nomes da edição Homens que Amamos. Uma manicure de São Paulo relatou que a tampa do esmalte é muito pontiaguda e acabou ferindo a palma da sua mão, por isso, recorreu a uma associação de consumidores, intitulada Proteste, para solicitar a retirada do produto do mercado e a reformulação de sua embalagem. Constatando o acidente de consumo, a Proteste encaminhou para o fabricante e para a Agência Nacional de Vigilância Sanitária (Anvisa), ofício com pedido de alteração da embalagem, com a alegação de que o produto estava em desacordo com o Código de Defesa do Consumidor por deixar de oferecer a segurança necessária. Também foi encaminhado ofício para o Departamento de Proteção e Defesa do Consumidor (DPDC), do Ministério da Justiça. A coordenadora institucional da Proteste, Maria Inês Dolci, afirmou que "neste caso, a tampa causou um acidente e por isso pedimos a retirada do produto para modificação da embalagem e não do esmalte em si. Todos os veículos responsáveis pela fiscalização estão notificados e devem acompanhar o caso". 
Imagem divulgada pela Proteste com o machucado na palma da mão da consumidora

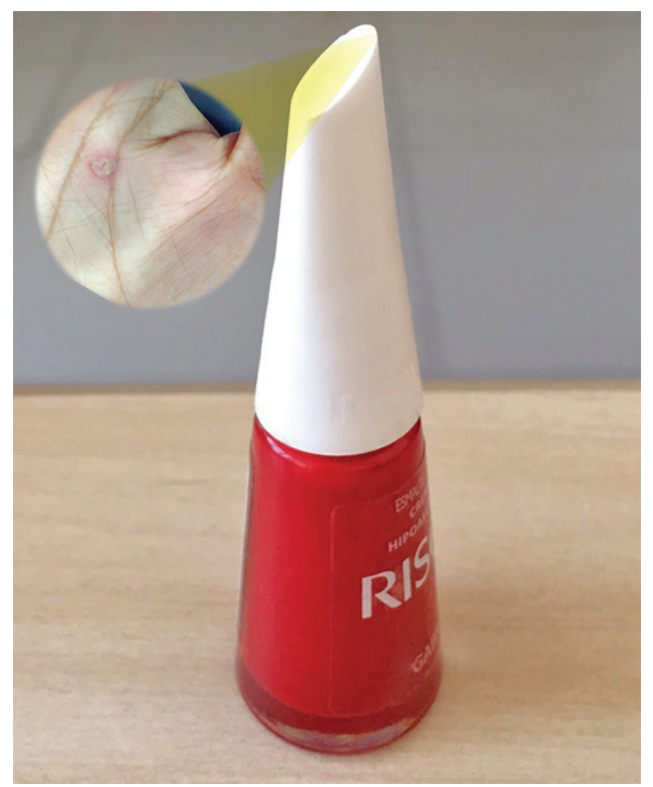

(Foto: Divulgação)

Vale ressaltar que a reclamação foi de apenas uma consumidora que, em nenhum momento entrou em contato com a marca. Porém, seu empoderamento desafiou todo o processo de produção de uma empresa internacional, presente no Brasil há décadas.

A Risqué respondeu alegando que a nova embalagem está no mercado desde julho de 2014 e que foi desenvolvida a partir de estudos e de pesquisas, realizados inclusive com manicures e consumidoras, que validaram sua funcionalidade e seu formato. A empresa exibiu, ainda, um laudo do Laboratório Falcão Bauer, que aprovou a tampa da embalagem por confirmar que não há risco de acidente de consumo.

Esse caso ilustra como a rede mundial de computadores pode ser um veículo de total força para consumidores e como a sua relação com as marcas e com as instituições sociais vêm sofrendo uma transformação sem precedentes.

O cenário torna-se ainda mais alarmante ao se constatar que se trata somente é apenas o início de uma era que ainda deverá trazer muitas alterações nas relações e na comunicação social e mercadológica. 
As transformações sociais que a internet trouxe vão além do acesso à conexão e a informações disseminadas em tempo real. O impacto vem ocorrendo de forma contundente na sociedade, nas instituições sociais e no relacionamento dos consumidores com as marcas. Ainda sem saber o que vem pela frente, o Estado e as organizações não sabem, ainda, como agir, ou reagir, a esse movimento que permite a todos ter voz. A comunicação passou a ser multicanal e, ao mesmo tempo, individualizada.

As instituições sociais estão assistindo a um levante de ciberativistas, que se unem por meio da rede, com o intuito de lutar por causas em que acreditam. Os ativistas digitais conseguem defensores em todo mundo e através de abaixo-assinados virtuais, engajam uma multidão e ganham força para suas reivindicações.

A sociedade passa a ser mais consciente e politizada pela circulação de informações antes restritas aos meios em que eram produzidas. Dessa forma, a luta pelos direitos coletivos ganha uma nova face ante a circulação da comunicação virtual, permitindo-se que a própria Democracia seja repensada.

Já as marcas se veem como reféns de seus clientes, que influenciam o comportamento de seus pares em redes sociais digitais, em blogs e em fóruns. Os consumidores, mais ativos do que nunca, exigem o direito de participar das decisões empresarias e contestam as escolhas das corporações.

Diante de um ambiente dialógico intenso, a única saída, às empresas, parece ser a abertura para o relacionamento com os atores tecnosociais, por meio do diálogo e da compreensão das emoções desse novo consumidor, uma forma eficaz de manter, as companhias, na mente e no coração dos internautas.

\section{REFERÊNCIAS BIBLIOGRÁFICAS}

CARPANEZ, J. Em suas mãos - ativismo digital. Disponível em: < $\underline{\text { http://tab.uol.com.br/ativismo- }}$ digital/> Acesso em 27/10/2015.

CASTELLS, M. A sociedade em rede. São Paulo: Paz e Terra, 1999 - 14 edição.

CASTELLS, M. Redes de Indignação e Esperança: movimentos sociais na era da internet. Rio de Janeiro: Editora Zahar, 2013.

CREMADES, J. Micropoder: a força do cidadão na era digital. São Paulo: Editora Senac 2009.

FIGARO, R. Relações de Comunicação no Mundo do Trabalho e as Comunicação nas Organizações. In: A Comunicação como Fator de Humanização das Organizações (Orgs) KUNSCH, M.M.K. São Caetano do Sul: Difusão Editora, 2010.

GALINDO, D. S. (Orgs) A Comunicação de Mercado em Redes Virtuais - uma questão de relacionamento. Chapecó: Argos, 2015. 
GONÇALVES, E. M. A Narrativa Complexa e o Envolvimento dos Sujeitos do Processo Comunicativo: clássicos conceitos de linguagem para novas narrativas. In: A Comunicação em Mercados Virtuais - uma questão de relacionamento. (Orgs) Galindo, D. Chapecó: Argos, 2015.

JENKINS, H. Cultura da Convergência. São Paulo: Editora Aleph, 2009.

KOTLER, P. Marketing 3.0: as forças que estão definindo o novo marketing centrado no ser humano. Rio de Janeiro: Elsevier, 2010.

NORDSTRÖM, K. e RIDDESTRALE, J. Funky Business - Talento Movimenta Capitais. São Paulo: Makron Books, 2001.

Disponível em: vejasp.abril.com.br/blogs/beleza-de-blog/2015/06/15/retirada-mercado-esmalte-tampa-pontiaguda-risque-proteste/?utm_source=redeabril_vejasp. Acesso em 21/10/2015.

Disponível em: http://www.egov.ufsc.br/portal/conteudo/ativismo-digital---mobilizando-sociedade-em-rede. Acesso em 27/10/2015.

Disponível em: http://mulher.uol.com.br/beleza/noticias/redacao/2015/03/23/marca-de-esmaltes-causa-polemica-ao-lancar-colecao-que-homenageia-homens.htm Acesso em 29/10/2015. 